
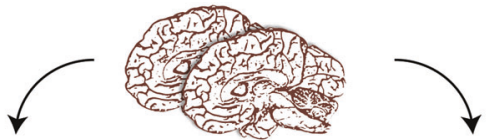

Homogenate Brain Tissue
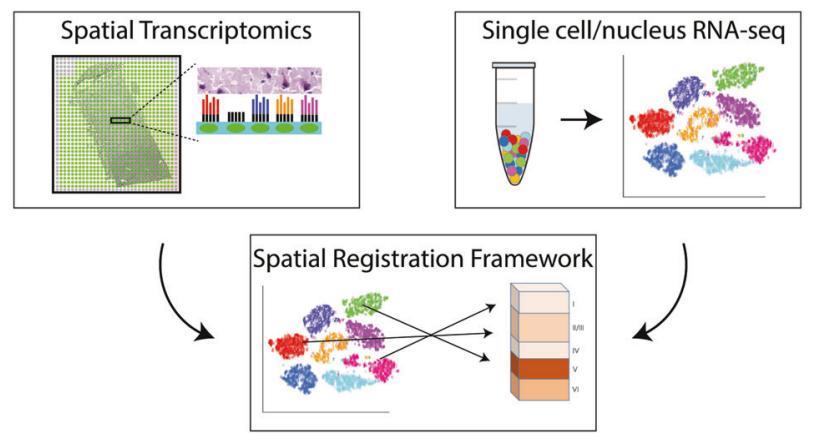

Fig. 1 Spatial resolution of cell-type-specific gene expression in the human brain. Bulk homogenate tissue contains heterogeneous cell types with distinct spatial orientations. Spatial transcriptomic approaches, such as SPATiAL, use spotted arrays with positional molecular barcodes that tag cDNA synthesized in intact tissue sections with a spatial location allowing gene expression to be mapped back to a histological image (i.e., specific cortical layers). Parallel sc/sn RNA-seq approaches define gene expression in individual cells dissociated from homogenate tissue. Integrating spatial transcriptomic data with sc/snRNA-seq data opens possibilities for adding anatomical dimensions to existing datasets, to better understand cell-type-specific molecular profiles in the human brain during development and psychiatric disease

genome-wide association study signals are preferentially enriched for synaptic neuropil transcripts [9].
FUNDING AND DISCLOSURE

Funding to support this research was provided by the Lieber Institute for Development. The authors declare no competing interests.

\section{ADDITIONAL INFORMATION}

Publisher's note: Springer Nature remains neutral with regard to jurisdictional claims in published maps and institutional affiliations.

REFERENCES

1. Jaffe $A E$, Irizarry RA. Accounting for cellular heterogeneity is critical in epigenomewide association studies. Genome Biol. 2014;15:R31.

2. Zheng SC, Breeze $C E$, Beck $S$, Teschendorff $A E$. Identification of differentially methylated cell types in epigenome-wide association studies. Nat Methods. 2018;15:1059-66.

3. Lein $E$, Borm LE, Linnarsson S. The promise of spatial transcriptomics for neuroscience in the era of molecular cell typing. Science. 2017;358:64-69.

4. Wang X, Allen WE, Wright MA, Sylwestrak EL, Samusik N, Vesuna S, et al. Threedimensional intact-tissue sequencing of single-cell transcriptional states. Science. 2018;361:eaat5691.

5. Burgess DJ. Spatial transcriptomics coming of age. Nat Rev Genet. 2019;20:317.

6. Rodriques SG, Stickels RR, Goeva A, Martin CA, Murray E, Vanderburg CR, et al. Slide-seq: a scalable technology for measuring genome-wide expression at high spatial resolution. Science. 2019;363:1463-7.

7. Ståhl PL, Salmén F, Vickovic S, Lundmark A, Navarro JF, Magnusson J, et al. Visualization and analysis of gene expression in tissue sections by spatial transcriptomics. Science. 2016:353:78-82.

8. Maniatis S, Äijö T, Vickovic S, Braine C, Kang K, Mollbrink A, et al. Spatiotemporal dynamics of molecular pathology in amyotrophic lateral sclerosis. Science. 2019;364:89-93.

9. Skene NG, Bryois J, Bakken TE, Breen G, Crowley JJ, Gaspar HA, et al. Genetic identification of brain cell types underlying schizophrenia. Nat Genet. 2018;50:825-33.

\title{
Role for kappa-opioid system in stress-induced cocaine use uncovered with PET
}

\author{
Derek Blevins $^{1}$ and Diana Martinez ${ }^{1}$ \\ Neuropsychopharmacology (2020) 45:233-234; https://doi.org/10.1038/s41386-019-0512-7
}

Cocaine use disorder (CUD) continues to affect nearly a million American adults. While significant efforts have been made to find an effective pharmacotherapeutic, primarily targeting the brain's reward system, there remain few treatment options. In the past 30 years, animal models and post-mortem human studies have elucidated the role of the dynorphin-kappa opioid receptor (KOR) system in the maintenance of cocaine use, particularly during the negative affect state, also termed the "dark side" of addiction [1]. Animal models have shown that blockade or genetic deletion of the KOR attenuates stress-induced cocaineseeking behavior [2]. Importantly, this effect is selective for stress: blocking the KOR does not change cocaine-primed reinstatement [2]. Post-mortem human studies have shown increases in KOR in limbic areas in fatal overdose victims [3].
However, there has been little advancement to evaluate the effects of KOR antagonists in individuals with CUD, despite the lack of currently available treatment options.

Our recent study sought to evaluate the association between the dynorphin-KOR system and a laboratory model of stressinduced relapse and binge cocaine use using positron emission tomography (PET) [4]. Imaging with the KOR selective agonist $\left[{ }^{11} \mathrm{C}\right] \mathrm{GR} 103545$ in volunteers with CUD showed a significant association between KOR binding and cocaine selfadministration following stress induced by a cold-pressor test. This result suggests that CUD individuals with higher levels of KOR binding are more prone to relapse to cocaine use under stressful conditions compared to those with lower levels of KOR availability. Additionally, after a 3-day cocaine binge in the

\footnotetext{
${ }^{1}$ Department of Psychiatry, Columbia University Irving Medical Center and the New York State Psychiatric Institute, New York, NY, USA
}

Correspondence: Diana Martinez (dm437@cumc.columbia.edu)

Published online: 9 September 2019 
laboratory, a subsequent PET scan showed reduced $\left[{ }^{11} \mathrm{C}\right]$ GR103545 binding compared to CUD subjects' baseline scans. This reduction in radioligand binding suggests that increased endogenous dynorphin is competing for KOR-binding sites and supports the prior animal literature showing that binge cocaine use modifies this neurotransmitter system. Together, these findings support the negative affect state hypothesis of addiction and implicate that the dynorphin-KOR system is a central part of this state in humans with CUD.

Prior to our combined human laboratory and PET imaging study, there was a limited understanding of the potential clinical role for KOR antagonists in CUD. A multi-site placebocontrolled trial of combined buprenorphine (a potent kappa antagonist and partial mu agonist) and extended-release naltrexone (a non-specific opioid receptor antagonist) showed mixed results [5], although this may have been affected by the mu receptor activity of naltrexone. More recently, a selective KOR antagonist LY2456302 was shown to be well-tolerated in CUD patients, showing feasibility for future clinical trials [6].

The confluence of data in animal models, post-mortem human studies, and now human PET imaging robustly supports the need for clinical studies of KOR antagonists that focus on stress-induced relapse. Future success with KOR antagonists will depend on targeting the "dark side" of addiction, by selectively recruiting participants who relapse in the setting of stress and dysphoria.

\section{FUNDING AND DISCLOSURE}

The authors declare no competing interests.

\section{ADDITIONAL INFORMATION}

Publisher's note Springer Nature remains neutral with regard to jurisdictional claims in published maps and institutional affiliations.

\section{REFERENCES}

1. Koob GF. Neurobiological substrates for the dark side of compulsivity in addiction. Neuropharmacology. 2009;56(Suppl 1):18-31.

2. Redila VA, Chavkin C. Stress-induced reinstatement of cocaine seeking is mediated by the kappa opioid system. Psychopharmacology (Berl). 2008;200:59-70.

3. Staley JK, Rothman RB, Rice KC, Partilla J, Mash DC. K2 opioid receptors in limbic areas of the human brain are upregulated by cocaine in fatal overdose victims. J Neurosci. 1997; 17:8225.

4. Martinez D, Slifstein M, Matuskey D, Nabulsi N, Zheng MQ, Lin SF. et al. Kappa-opioid receptors, dynorphin, and cocaine addiction: a positron emission tomography study. Neuropsychopharmacology. 2019;44:1720-7.

5. Ling W, Hillhouse MP, Saxon AJ, Mooney LJ, Thomas CM, Ang A, et al. Buprenorphine +naloxone plus naltrexone for the treatment of cocaine dependence: the Cocaine Use Reduction with Buprenorphine (CURB) study. Addiction (Abingdon, Engl). 2016;111:1416-27.

6. Reed B, Butelman ER, Fry RS, Kimani R, Kreek MJ. Repeated administration of Opra Kappa (LY2456302), a novel, short-acting, selective KOP-r antagonist, in persons with and without cocaine dependence. Neuropsychopharmacology. 2018;43:739-50.

\title{
Targeting neuroinflammation with brain penetrant $\mathrm{P} 2 \mathrm{X} 7$ antagonists as novel therapeutics for neuropsychiatric disorders
}

\author{
Anindya Bhattacharya ${ }^{1}$ and Marc Ceusters ${ }^{2}$ \\ Neuropsychopharmacology (2020) 45:234-235; https://doi.org/10.1038/s41386-019-0502-9
}

Several lines of scientific data suggest a correlation between neuroinflammation and CNS disorders such as multiple sclerosis, Alzheimer's disease, Parkinson's disease, epilepsy, chronic pain and neuropsychiatric disorders (depression, bipolar disorder and schizophrenia). Many of these CNS diseases are comorbid with classical peripheral inflammatory disorders such as rheumatoid arthritis, inflammatory bowel disease, psoriasis, to name a few. The scientific underpinning of this comorbidity in patients is perhaps driven by a compromised immune surveillance system wherein the immune cells and cytokines/chemokines in the periphery cross-talk to the CNS either directly (BBB integrity compromise) or indirectly via modulating meningeal immunity. In addition, there is an inherent 'central' component of neuroinflammation that is driven by microglial cells within the CNS. As such, neuroinflammatory drug targets on microglia cells within the CNS have been an emerging area of research within the neuroscience community, both in academia, industry and in public-private consortia.

P2X7 is an ATP activated ion channel, that is expressed abundantly on microglia (and peripheral immune cells) and is a critical mediator of neuroinflammation via release of NLRP3 dependent IL-1 $\beta$ and IL18 [1]. In several preclinical models of stress in rodents, independent research groups have demonstrated an activated NLRP3-IL1 $\beta$ pathway; as such intervention of this pro-inflammatory pathway by targeting the P2X7 ion channel with CNS penetrant antagonists have demonstrated efficacy in models of psychiatric diseases [2] and provides optimism for novel therapeutic options for patients with mood disorders. When ATP is present in high concentrations in extracellular space as a danger signal, the P2X7-NLRP3- IL1 $\beta$ signaling is activated initiating the microglial neuroinflammatory cascade. The functional expression of this pathway may or may not be associated with enhanced expression of P2X7 at the protein level

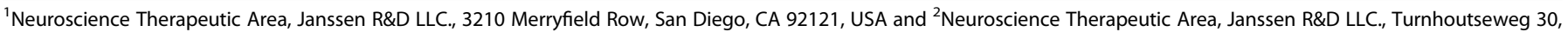
Beerse 2340, Belgium

Correspondence: Anindya Bhattacharya (abhatta2@its.jnj.com)

Received: 18 July 2019 Revised: 16 August 2019 Accepted: 20 August 2019

Published online: 2 September 2019 